\title{
Colostrum Antibodies, Egg Antibodies and Monoclonal Antibodies Providing Passive Immunity for Animals
}

\author{
Dan DuBourdieu
}

\begin{abstract}
Passive immunity can be provided to animals by several sources of antibodies including from colostrum, avian eggs, and monoclonal sources. These antibodies have been shown protect production and companion animals from a number of pathogens. This chapter reviews the immune system for the principles of immune response to antigens and the synthesis of immunoglobulins of the five classes of antibodies in the body. Colostrum antibodies are described for passive immunity protection in animals such as calves. Chicken egg antibodies are another source of antibodies for passive immunity. Therapeutic monoclonal antibodies are also used to provide passive immunity in the veterinary field.
\end{abstract}

\section{Keywords}

Passive immunity · Colostrum antibodies · Egg

antibodies · Monoclonal antibodies

\section{Introduction}

The use of antibodies by veterinarians to maintain the health of animals has a long history. Fundamentally, when it comes to the immune system health of production and companion animals, there are little absolute differences in the intended purpose of the immune system. Mammals have the same basic immune system with minor differences between the species. Even the differences between birds and mammals are not so great since the purpose of the immune system is to keep infectious microorganisms, such as certain bacteria, viruses, and fungi, out of the body and to destroy any infectious microorganisms that do invade the body. How veterinarians take advantage of the immune system to

D. DuBourdieu $(\triangle)$

Vets Plus Inc., Menomonie, WI, USA

e-mail: dand@vets-plus.com maintain health can roughly be defined as taking advantage of the body's inherent method of maintaining health through adaptive immunity provided by vaccinations to generate antibodies inside the animal or by administering preformed antibodies to an animal through a process called passive immunity.

\section{The Immune Response}

Evolution has produced an amazing immune system in animals that utilizes various cell types and proteins to protect them from invasive organisms. This system has two broad categories: nonadaptive and adaptive. The nonadaptive immune system is mediated by cells that respond in a nonspecific manner to foreign substances. This response includes phagocytosis by macrophages, secretion of lysozymes by lacrimal cells, and cell lysis by natural killer cells. The adaptive immune response is mediated by lymphocytes that produce a set of proteins called antibodies that are either secreted by or found on the surface of the lymphocyte. When the antibodies themselves are created within the animal following vaccination or from exposure to pathogens, the process is called adaptive immunity. When preformed antibodies from a host animal are given to another recipient animal, such as it offspring or even a completely different species animal, the process is called passive immunity.

\section{$3 \quad$ Veterinary Vaccines for Active Immunity}

Scientists have long taken advantage of the adaptive immune system by using vaccines.

Vaccines for animal diseases were the first to result from laboratory-based scientific investigation. French chemist Louis Pasteur developed a vaccine for chicken cholera in 1879, and one for anthrax of sheep and cattle in 1881. 
The major goals of veterinary vaccines are to improve the health and welfare of companion animals, increase production of livestock in a cost-effective manner, and prevent animal-to-human transmission from both domestic animals and wildlife. These diverse aims have led to different approaches in the development of veterinary vaccines from crude but effective whole-pathogen preparations to molecularly defined subunit vaccines, genetically engineered organisms or chimeras, vectored antigen formulations, and naked DNA injections (Meeusen et al. 2007). It has also resulted in various guidelines for vaccinations of companion animals such as for dogs (Ford et al. 2017) and production animals such as swine (Alabama and Auburn 2018), in poultry (Stewart-Brown 2018), cow/calf (Missouri 2018), and other production animals. Successful veterinary vaccines have been produced against viral, bacterial, protozoal, and multicellular pathogens, which in many ways have led the field in the application and adaptation of novel technologies.

\section{$4 \quad$ Passive Immunity}

Whereas active immunity refers to the process of exposing the individual to an antigen to generate an adaptive immune response, passive immunity refers to the transfer of antibodies from one individual to another (Marcotte and Hammarström 2015). Passive immunity provides only short-lived protection, lasting from several weeks to up to 3-4 months, but is immediate. Nature intended passive immunity to occur when maternal antibodies are transferred to the fetus through the placenta or from breast milk to the gut of the infant. However, it can also be produced artificially when antibody preparations are derived from sera or secretions of immunized donors and are delivered via oral or systemic routes to nonimmune individuals. Passive immunization is a new approach to providing protection to animals against pathogens because of the emergence of new and drug-resistant microorganisms, diseases that are unresponsive to drug therapy and individuals with an impaired immune system who are unable to respond to conventional vaccines.

\section{$5 \quad$ Antibodies}

The immune system can respond specifically to millions of different molecules and is constantly challenged by huge numbers of antigens. A major feature of the immune system is that it can synthesize a vast number of antibodies. Each of these antibodies can bind to a different antigen. This binding is the basis for the molecular specificity of the immune response.

Antibodies are proteins produced by a type of terminally differentiated B lymphocytes. B cells take the B name from chicken bursa cells where they were first discovered (Gitlin and Nussenzweig 2015). Antibodies are produced in response to the presence of foreign molecules in the body. The antibodies circulate throughout the blood and lymph where they bind to the foreign antigens. Once bound, these antibody-antigen complexes are removed from circulation, primarily through phagocytosis by macrophages. This is the basis for antibodies protecting the animal against pathogens.

Antibodies are a large family of glycoproteins that share key structural and functional features. From a structure standpoint, antibodies look like a Y-shaped molecule (Fig. 1). Each Y contains four polypeptides. Two of the polypeptides are identical and called heavy chain. The other two, also identical, are called light chain and are connected by disulfide bonds. There are five classes of antibodies, IgG, IgM, IgA, $\operatorname{IgE}$, and $\operatorname{IgD}$, that are classified based on the number of Y-like units and the type of heavy-chain polypeptide they contain (Fig. 2).

\section{$6 \quad$ Antibody Classes}

IgM is the largest antibody, and it is the first to appear in response to initial antigen exposure. The spleen, where plasma cells responsible for antibody production reside, is the major site of specific IgM production (Capolunghi et al. 2013; Marchalonis et al. 2002). IgG is the main type of antibody found in blood and extracellular fluid allowing it
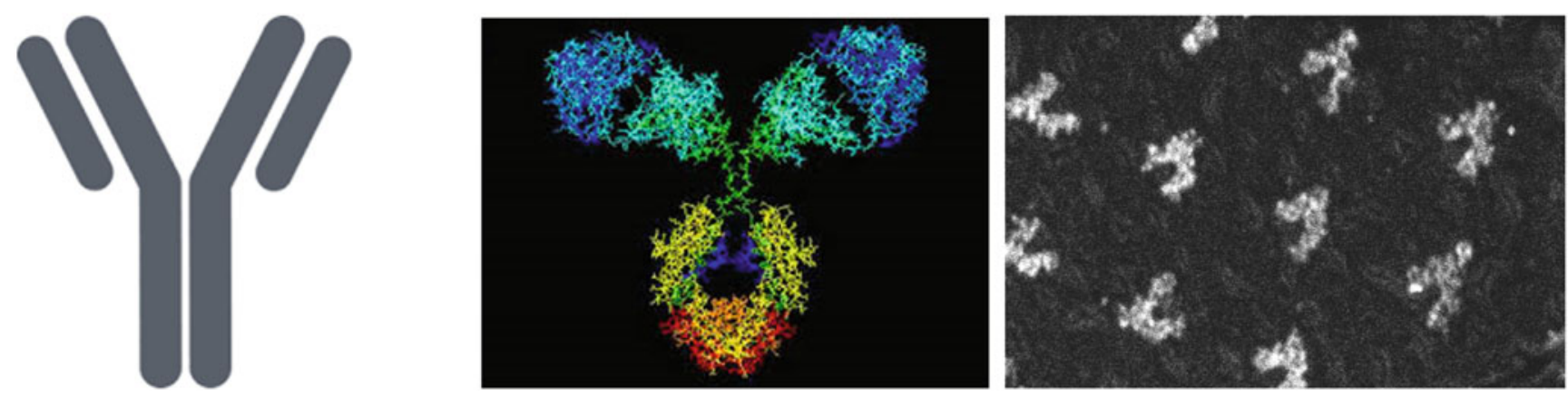

Fig. 1 Antibody structure as drawn, by protein model and by electron microscopy 
Fig. 2 Structures of the five classes of antibodies

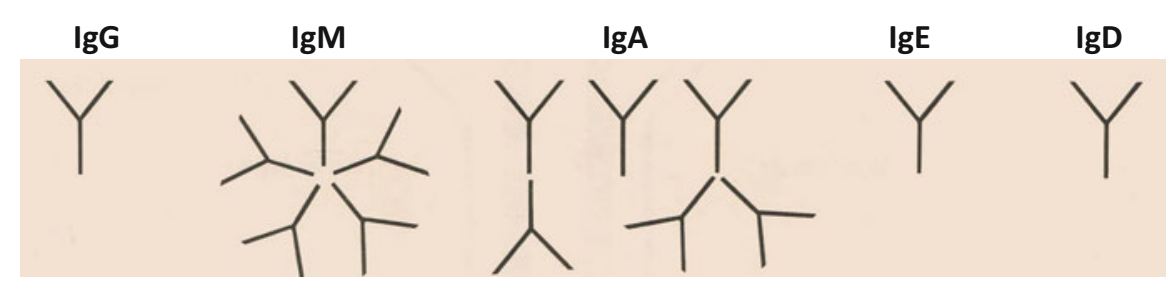

to control infection within body tissues. Approximately $80 \%$ of all antibodies in humans and companion animals are of the IgG class. Immunoglobulin A (IgA) plays a crucial role in the immune function of mucous membranes. The amount of IgA produced in association with mucosal membranes is greater than all other types of antibodies combined (Fagarasan and Honjo 2003; Holmgren and Czerkinsky 2005; Snoeck et al. 2006). $\operatorname{IgD}$ was initially thought to be a recently evolved antibody class because it was only detected in primates, mice, rats, and dogs and not guinea pigs, swine, cattle, sheep, and frogs (Preud'homme et al. 2000). However, recent discoveries of IgD in ancient vertebrates suggest that IgD has been preserved in evolution from fish to humans for important immunological functions (Chen and Cerutt 2011). Immunoglobulin $\mathrm{E}$ ( $\mathrm{IgE}$ ) has only been identified in mammals. IgE's main function is immunity against parasites such as helminths (Erb 2007) like Schistosoma mansoni, Trichinella spiralis, and Fasciola hepatica (Watanabe et al. 2005; Pfister et al. 1983). IgE also has an essential role in type I hypersensitivity (Gould et al. 2003) which manifests in various allergic diseases, such as allergic asthma, most types of sinusitis, allergic rhinitis, food allergies, and specific types of chronic urticaria and atopic dermatitis (Mueller et al. 2016).

\section{$7 \quad$ Antibody-Antigen Interactions}

Antibodies bind antigens at the upper tips of the Y molecule. The region of antigen where binding occurs is called the epitope (Fig. 3).

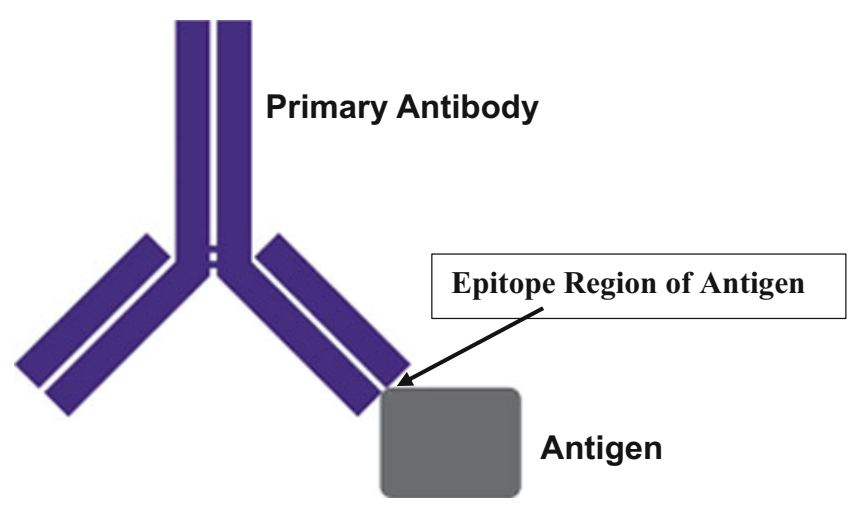

Fig. 3 Antibody binding to an antigen
Antibodies can bind to a wide range of chemical structures and can discriminate among related compounds. How well the antibody binds to an antigen is known as affinity. This affinity can range from low to high.

\section{Colostrum and Passive Immunity}

Mammals are born without a fully functional adaptive immune system even though the basic elements are present. When a mammal is born, it emerges from the sterile uterus into an environment where it is immediately exposed to a host of microorganisms. The gastrointestinal tract (GIT) acquires a complex microbial flora within hours. If it is to survive, the newborn animal must be able to control this microbial invasion. In practice, the adaptive immune system takes some time to become fully functional, and innate mechanisms are responsible for the initial resistance to infection. In some species with a short gestation period, such as mice, the adaptive immune system may not even be fully developed at birth. In animals with a long gestation period, such as domestic mammals, the adaptive immune system is fully developed at birth but cannot function at adult levels for several weeks. The complete development of active immunity depends on antigenic stimulation. The proper development of B cells and B-cell receptor diversity requires clonal selection and antigen-driven cell multiplication. Thus, newborn mammals are vulnerable to infection for the first few weeks of life. They need assistance in defending themselves at this juncture. Temporary help is provided by the mother in the form of colostrum, which contains antibodies. The passive transfer of immunity from mother to newborn is essential for survival.

Calves are born without an active immune system and rely on the consumption of antibodies for protection from disease such as scours and pneumonia. The cow provides its calf with nutrients for growth and development during gestation, but the cow cannot directly provide the calf with antibodies to protect it from diseases. Fortunately, immunoglobulins form an important component of the immunological activity found in milk and colostrum. While humans have a large amount of IgA in their colostrum, the colostrum from most other animals contains a high percentage of IgG (Hurley and Theil 2011) (Fig. 4). Immunoglobulins found in mammary secretions arise from systemic and local sources. In the case 


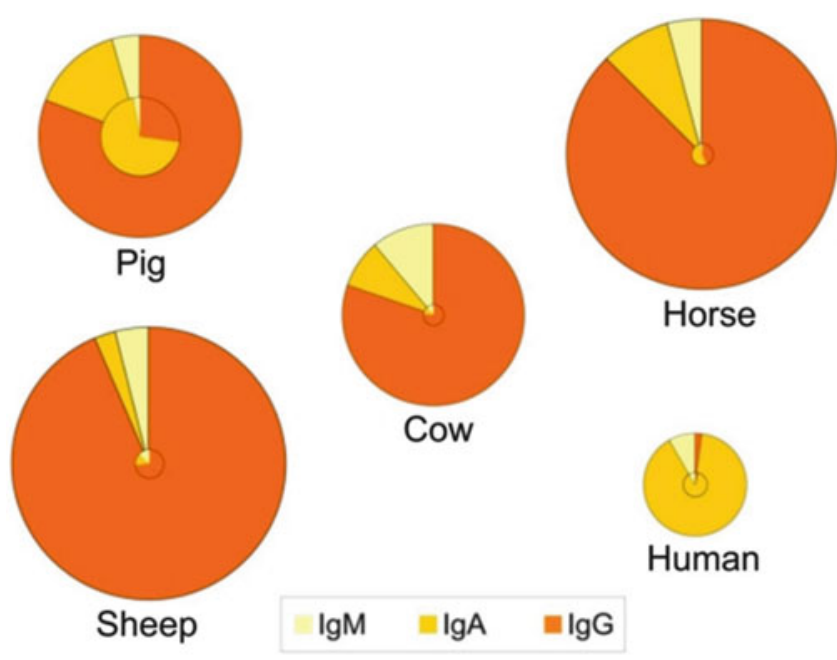

Fig. 4 Relative distribution of $\operatorname{IgG}$, IgA, and IgM in colostrum (outer circle) and in milk (inner circle) of five species

of $\mathrm{IgG}$ in milk, the major portion comes from the serum (Mayer et al. 2005). While plasma cells producing IgG may occur within the mammary tissue, their contribution to the $\mathrm{IgG}$ in colostrum is minor compared with the IgG derived from serum.

The other major classes of immunoglobulins transported into colostrum and milk are IgA and IgM. Immunoglobulin A (IgA) is the major immunoglobulin in human colostrum and milk; however, it is also present in milk of most other species. Colostrum and milk IgA and IgM are found in the form of secretory IgA, or $\operatorname{sIgA}$, and $\operatorname{sIgM}$. Much of this is produced by plasma cells in the mammary tissue. The plasma cells are part of the gut-associated lymphoid tissue (GALT), the largest immune organ of an organism, which includes the Peyer's patches, lymphoid and myeloid cells in the lamina propria, and intraepithelial lymphocytes (Ishikawa et al. 2005). Interestingly enough, more than $70 \%$ of the immune system is located in the gastro intestinal tract, the site where many oral pathogens first interact with an animal (Vighi et al. 2008). GALT is a part of the mucosa-associated lymphoid tissue and works in the immune system to protect animals from invasion of pathogens in the gut. One of the physiological functions of the mucosa in the gut is for food absorption. However, of equal importance of the GALT is in the body's defense, due to its large population of plasma cells whose number exceeds the number of plasma cells in the spleen, lymph nodes, and bone marrow combined (Nagler-Anderson 2001).

Lymphocytes from the GALT system will move to the mammary gland and provide a direct link between the antigen exposure response in the mother's mucosa system and the secretory immunoglobulins of the mammary gland (Brandtzaeg 2010). As such, this means that maternal colostrum and milk will contain antibodies specific for pathogens that may be encountered by the neonate's intestine and other mucosal tissues. This provides a rationale for the observations that bovine colostrum from nonimmunized cows may also afford passive immune protection against human pathogens in both humans and animals (Li-Chan et al. 1994; Yolken et al. 1985) and opens the door to new technology to provide veterinarians another way to protect animals from pathogens that does not involve antibiotics.

Antibodies must be obtained by drinking colostrum within the first couple of hours after birth as part of the passive immunization system in order to maximize antibody absorption (Pakkanen and Aalto 1997). Like other animals, antibodies are generated by healthy cows as a result of every day exposure to infectious agents. Antibodies can also be the result of specific vaccination programs. The cow's natural antibodies to these infectious agents are passed from the cow to the calf through colostrum. The level of antibodies transmitted from the cow through the colostrum can be elevated by a pre-calving vaccination program (Thomas 2017).

When the calf drinks colostrum, the maternal derived antibodies are absorbed from the calf's GIT into the blood stream. Some of the immunoglobulins also remain in the gut where they can neutralize pathogenic bacteria and help prevent the development of diarrhea. The absorption of antibodies from the GIT into the bloodstream is called passive transfer. Failure of passive transfer (FPT) in dairy calves is defined by a blood IgG level of $<10 \mathrm{mg} / \mathrm{mL} 24-48 \mathrm{~h}$ after birth (Stilwell and Carvalho 2011). Calves that experience FPT are more likely to become sick or die in the first 2 months of life than calves with adequate immunity. Many factors can contribute to FPT, but colostrum and the management of colostrum feeding are often involved. To successfully obtain passive transfer and provide the calf with protection from diseases, it is thought that the calf needs to consume a minimum of 150-200 g of immunoglobulins (Meganck et al. 2014).

The pathway between the gastrointestinal tract and the bloodstream is only open for a short window of time. Research shows that this pathway starts to close shortly after birth, and after 8-12 h, approximately $50 \%$ of the calf's ability to absorb colostrum antibodies is gone. It has therefore been recommended to feed calves as much colostrum as they want by bottle within 1-4 h after birth and at $12 \mathrm{~h}$ of age to substantially reduce the probability of FPT (Chigerwe et al. 2009; Trotz-Williams et al. 2008).

Colostrum also provides the calf with protein, energy in the form of fat and sugar, and vitamins (Quigley and Drewry 1998). Some vitamins do not cross the placental barrier, and colostrum is the primary source of these nutrients for the calf after birth. Energy is required for all metabolic functions including maintenance of body temperature. One of the leading causes of death in dairy calves is failure to initiate breathing and metabolic processes in the first hours of life. The 
newborn calf only has a few hours of energy reserves in stored fat and therefore needs the energy from colostrum. Research also confirms that the sooner a calf consumes colostrum, the more maternal antibodies it can utilize.

The quality of colostrum is a major issue that the dairy industry faces on a regular basis. Generally speaking, quality of colostrum is related to the amount of antibody that is present. Colostral $\mathrm{IgG}$ concentration is an important factor that affects whether calves receive sufficient passive immunity (Godden et al. 2012). Unfortunately, the amount of IgG in maternal colostrum varies dramatically among cows ( $<1-235 \mathrm{~g} / \mathrm{l})$ with $29.4-57.8 \%$ of samples that do not reach the desired amount of $50 \mathrm{~g} \mathrm{IgG/l} \mathrm{(Gulliksen} \mathrm{et} \mathrm{al.}$ 2008). Colostral quality is difficult to estimate by the farmer based on produced volume or appearance of the colostrum. There are many variables that impact colostrum quality, including nutrition, the time the cow is milked, heat stress, and stage of lactation. A study from Iowa State University suggests that a minimum $30 \%$ of dairy calves in the USA are currently being fed colostrum classified below industry standards for IgG content and are at a greater risk of FPT, mortality, and morbidity (Morrill et al. 2011).

Other production mammals such as piglets face the same issues as calves for colostrum quality. Studies have shown that on average $25 \%$ of pigs with a colostrum intake below $200 \mathrm{~g}$ usually die. In pigs with a colostrum intake below $100 \mathrm{~g}$, mortality was as high as 65\% (Devillers et al. 2011). Giving spray-dried bovine colostrum to other animals such piglets has been shown (Sty et al. 2006) to help protect against gut dysfunction and inflammation. It may be possible that using bovine colostrum for piglets could help supplement sow colostrum. Research has also been done in foals with an enhanced bovine colostrum supplementation (Fenger et al. 2016).

\section{Colostrum Programs}

Since up to $50 \%$ of cows have colostrum with an $\mathrm{IgG}$ level below $50 \mathrm{mg} / \mathrm{mL}$, which will not prevent FPT, a variety of programs and protocols have been implemented by dairy producers. High-quality maternal colostrum is still the gold standard for feeding newborn calves. However, colostrum supplement and replacer products can be valuable tools to increase calf immunity when colostrum supplies are limited or disease eradication is desired. Colostrum products that contain IgG are regulated by the USDA Center for Veterinary Biologics and are available in bolus, gel, and powder formats. Supplement products are unable to raise the blood concentration of $\operatorname{IgG}$ above the species standard, which is $10 \mathrm{mg} / \mathrm{mL}$ for calves. Any product that is able to raise serum $\operatorname{IgG}$ concentration above $10 \mathrm{mg} / \mathrm{mL}$ may be called a colostrum replacer (Penn State 2017). Supplements do not contain sufficient quantities of antibodies to raise the blood $\operatorname{IgG}$ level in calves beyond what average quality colostrum will do. Colostrum replacer contains greater levels of $\operatorname{IgG}$ and other nutrients and provides an effective, convenient method of providing passive immunity to calves when maternal colostrum is not available.

Colostrum supplements available today are made from dried bovine colostrum or serum and contain 40-60 g of IgG per dose (9-13\% globulin protein). The fat content of these products ranges from 0.5 to $15 \%$. Spray-dried colostrum with high concentrations of immunoglobulin may be produced economically and used as an effective and convenient colostrum replacer in newborn calves (Chelack et al. 1993). Numerous products designed to replace colostrum are now on the market. These products are made from bovine colostrum or serum and contain 100-150 g of IgG per dose. These products also provide fat, protein, vitamins, and minerals needed by the newborn calf, although the amount varies between products. A summary (Pennsylvania State University 2017) of treatment means from 26 published studies investigating colostrum products indicated that replacer products provided an average of $157 \mathrm{~g}$ of $\mathrm{IgG}$, with an absorption efficiency of $31 \%$, and serum IgG of $12 \mathrm{mg} / \mathrm{mL}$. Supplement products (fed in addition to colostrum) provided $136 \mathrm{~g}$ of IgG with $19 \%$ absorption efficiency and resulted in serum $\mathrm{IgG}$ of $9 \mathrm{mg} / \mathrm{mL}$.

It has been recognized that while antibodies found in colostrum can certainly reduce diseases in animals via passive immunity when given to a newborn, they will only work if the colostrum donor animal has been exposed either naturally to the disease or given a vaccine to the disease, in order to have specific antibodies produced. Bovine colostrum that is typically spray-dried for supplements or replacer will contain only the antibodies that the cow may have encountered naturally. Therefore, the colostrum used may not have specific antibodies against particular diseases that a producer might be interested in. The animal industry has recognized this issue and has developed methods to produce specific antibodies in high titer against specific diseases that can be delivered in colostrum products. This is achieved by hyperimmunizing animals such as cows against specific animal diseases, collecting colostrum and processing it into powders such as by freeze-drying methods and then giving to a newborn ani$\mathrm{mal}$ in gels or boluses. A number of diseases including bacterial diseases like E. coli (Selim et al. 1995) and viral diseases such as rotavirus and coronavirus (Combs et al. 1993) or coccidial diseases such as giardia or cryptosporidia (Graczyk et al. 1999; Fayer et al. 1989; Naciri et al. 1994) have been researched for hyperimmunized colostrum efficacy. The hyperimmunized colostrum is collected, processed, and given to newborn calves. To varying degrees of success, these hyperimmunized colostrum antibodies have been proven to be successful in providing passive immunization. 
Besides calves, research has been done in a variety of production animals using bovine or other sources of colostrum. For example, lambs have been supplemented with ewe colostrum as well as hyperimmunized serum from sheep against $E$. coli (Pommer 2010). Other research has examined vaccination of cows with clostridial antigens and passive transfer of clostridial antibodies from bovine colostrum to lambs (Clarkson et al. 1985). Piglets have also been given passive protection against porcine epidemic diarrhea by hyperimmune bovine colostrum (Shibata et al. 2001).

Specific antibodies in a hyperimmunized colostrumderived product can be used while complementing early colostrum feeding and can be delivered at the same time as colostrum. There are some advantages to this strategy as specific immunoglobulins immediately fight at the gut level to protect against diseases that destroy the intestinal lining while also allowing for antibodies to be absorbed into the bloodstream. It's important to protect the intestinal lining because if the cells that line the digestive tract become damaged, milk cannot be digested or absorbed by the calf.

\section{Vaccination of Newborn Animals While Receiving Colostrum}

Besides the quality of the colostrum itself, researchers first believed that calves could not be vaccinated effectively while they had circulating maternal antibodies from the colostrum in their system. Preweaning calves can respond to vaccination stimulation as early as 1 month of age. The maternal antibodies absorbed from colostrum, however, cannot distinguish between the antigens of a natural challenge and the antigens in a vaccine. Therefore, colostrum antibodies can interfere with the immune response to a vaccination (Niewiesk 2014). Work continues to be done to develop ways to circumvent maternal antibody interference.

Vaccination of calves in the face of maternal antibodies (IFOMA) often does not result in seroconversion as maternally derived immunity interferes with the activation of adequate antibody responses to vaccination. However, it can prime $\mathrm{T}$ - and $\mathrm{B}$-cell memory responses that protect calves against clinical disease when maternal immunity has decayed. The activation of B- and T-cell memory responses in calves vaccinated IFOMA varies and is affected by several factors, including age, level of maternal immunity, type of vaccine, and route of administration. These factors influence the adequate priming of humoral and cell-mediated immune responses and the outcome of vaccination. Failure to adequately prime immune memory after vaccination IFOMA could result in lack of clinical protection and an increased risk of viremia and/or virus shedding (Chamorro et al. 2016).
There is obviously some controversy about whether newborn calves should be vaccinated (Cook et al. 2003). It is thought that the process of the calf mounting an immune response to a vaccine requires energy that could better be used to fight off disease and gain weight and the response could actually be detrimental to the early health of that calf. On the other hand, while maternal antibodies can block response to vaccination, sometimes they do not (Woolums 2007). The exact immunologic outcome in calves vaccinated IFOMA can vary, and this variation likely depends on many factors. These factors are not well characterized but likely include the nature of the vaccine administered, number of doses administered, age of the calf and level of maternal antibody present in the calf, and the means by which a protective response is defined. Guidelines for vaccinating newborn animals such as calves require additional research to clarify the IFOMA vaccination reactions.

\section{Antibody Products}

Fortunately, producers also have the option of using antibody products in order to generate immediate protection in situations where colostrum quality is poor. Antibody products complement colostrum feeding because they can be fed at the same time. These products are available in bolus, gel, and powder form. They also are included in some colostrum replacer and supplement formulas for added value. Typically, the antibody products are from hyperimmunized cows, and the specific antibody is found in the colostrum. The colostrum is processed and typically fractionated into a semi-purified preparation of antibody that is freeze-dried and put into capsules or boluses. Because antibody boluses can be fed in conjunction with colostrum, they can be a tool to help the calf not only achieve adequate passive transfer but also provide enough specific antibodies to protect against the most common early calf hood diseases.

Antibody products do not require the calf to react to a vaccine in order to develop antibodies. Rather specific antibodies against various diseases are already present, measured, and verified to be at a high enough level to protect the calf from scour-related diseases, and they can be fed as close to birth as possible. United States Department of Agriculture (USDA)-approved antibody products are available on the market that can be fed in conjunction with colostrum and provide the calf with immediate immunity. These antibodies go to the gut to immediately bind and neutralize diarrhea antigens while also being absorbed into the blood stream for extended protection (Combs et al. 1993; Chamorro et al. 2014). Another advantage of this approach is that providing specific antibody can potentially avoid vaccine stimulation. 
Fig. 5 Structure of mammalian IgG compared to avian $\mathrm{IgY}$

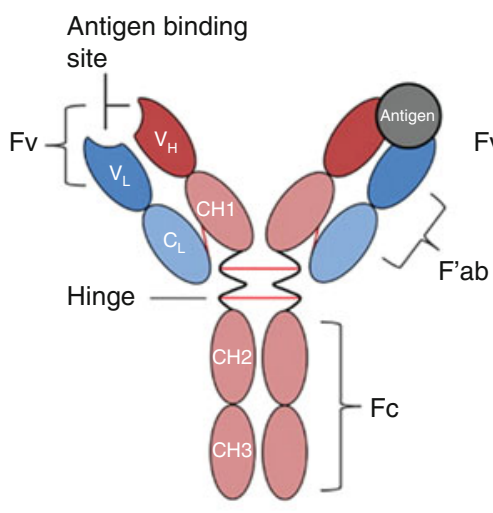

Mammalian IgG

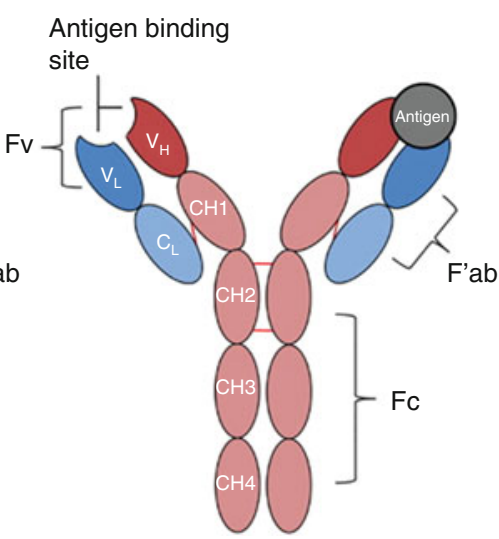

Avian IgY
Avoiding vaccine stimulation can allow a calf to conserve its minimal supply of fat and nutrients that are critical to get the calf through its first few days of life.

\section{Passive Immunity by Egg Antibodies}

Cows pass their immunity to their offspring by colostrum, and various colostrum products are on the market to achieve passive immunity. Additional sources of antibody products can be utilized in a similar manner to achieve passive immunity. These are from avian sources such as chickens. In birds, passive transfer of immunity occurs through the egg. By hyperimmunizing chickens over a period of time with inactivated multivalent bacterial or viral vaccines, this procedure results in the production of polyclonal immunoglobulins of the IgY class (specific to avians) directed against the stimulating organisms.

Oral consumption of the "immune" eggs containing specific IgY antibodies protects the animal against the specific organism(s) with which the hen was stimulated. Unfortunately, the eggs really cannot be cooked since heat dentures the antibodies found in the eggs. Other physical parameters such as an acidic $\mathrm{pH}$ will also destroy the antibodies to a certain extent. However, enough orally administrated $\operatorname{IgY}$ may survive passage through the GIT and, after excretion, still retain a great deal of its antigen-binding ability indicating that orally administrated IgYs are useful for passive immunity.

\section{3 Eggs as a Natural Source
of Immunoregulatory Factors}

Just as immune protection is transferred in utero in mammals or passively by a lactating mother via colostrum, hens passively transfer protection to their young by secreting immunoglobulin and other immune factors into their eggs for use by the hatching chick. The transfer of chicken immunoglobulins from the hen's serum to the yolk and from the yolk to the chick is analogous to cross-placental transfer of IgG from the mammalian mother to its offspring. While $\operatorname{IgM}$ and $\operatorname{IgA}$ are found in chicken eggs, the principle immunoglobulin is IgY which is found in the yolk of the egg (Hamal et al. 2006). IgY (Y stands for yolk) is an immunoglobulin class specific to avians and analogous in function to that of mammalian immunoglobulins. IgY has a similar structure as mammalian IgG with some minor differences in the heavy chains (Fig. 5).

Both eggs and milk (including breast milk) contain naturally occurring antibodies, and there are reports of immunomodulatory factors in milk as well (Li et al. 2017). However, immunoglobulin levels in eggs can be significantly higher than levels found in serum or milk (Woolley and Landon 1995). This may not be surprising since mammals have a considerably longer time of weeks or months during which they may passively transfer immunoglobulin and immune factors, while the hen has a single opportunity (the egg) to transfer all necessary survival components to its offspring. All the aspects that the chick needs to survive must be in the egg. Because egg products are a common source of protein in human diets and eggs contain antibodies and immune factors, it was obvious to utilize egg antibodies to provide passive immunity to animals. As such, this has resulted in a number of commercial egg antibody products on the market for production animals as well as companion animals to prevent various diseases. With few exceptions, oral consumption of specific antibodies has been reported (Diraviyam et al. 2014) to protect both humans and animals. Furthermore, in vitro studies with specific $\operatorname{IgY}$ antibodies have been found to inhibit processes associated with bacterial growth, adhesion to intestinal cells, and toxin production (Sugita-Konishi et al. 1996).

Meta-analysis has demonstrated the beneficial effects of IgY (Diraviyam et al. 2014) for a variety of animals. This 
Fig. 6 Vaccination for specific antibodies and processing egg yolk strategies

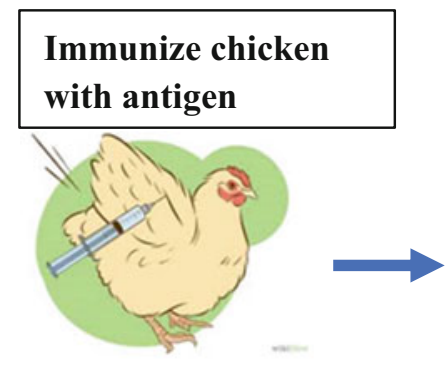

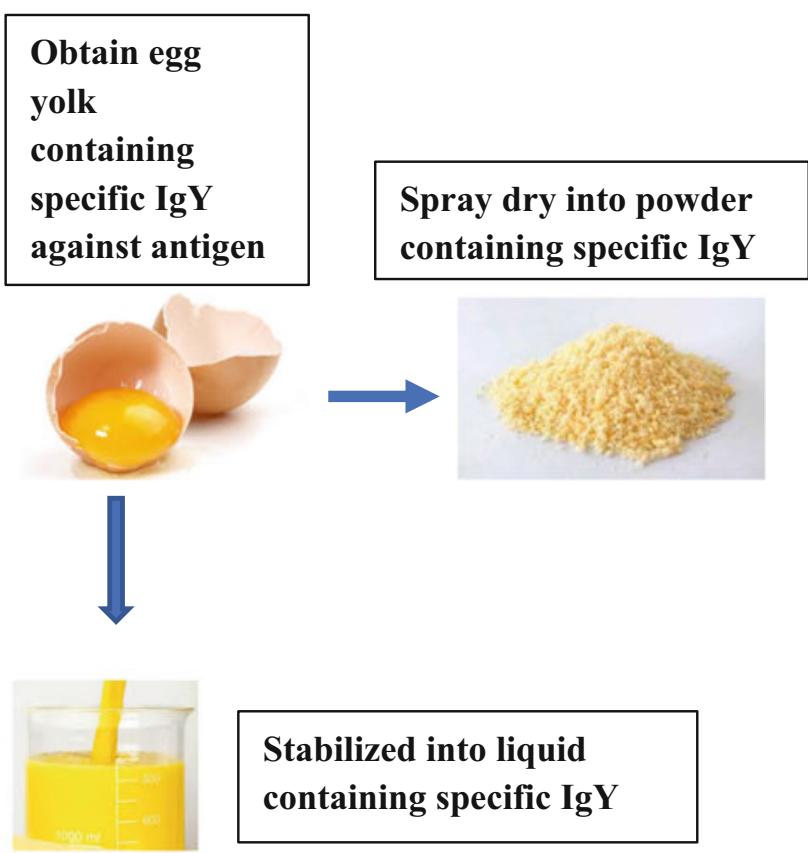

After appropriate times following vaccination, eggs are collected from the specially designated chicken flocks, washed and broken, and the yolk and egg white are typically dried to a fine proteinaceous powder. Various processes have been developed to help minimize heat damage to egg antibodies and immunoregulatory factors during the spraydrying procedure. However, spray-drying eggs can denature the IgY to an extent, due to at least some heating during the process. Keeping the egg away from heat is an optimal way of maintaining IgY titer levels and efficacy. While freezedrying is an expensive option for maintaining antibody titer levels, simply feeding fresh immunized eggs is another method which exists. This is to keep the immunized eggs in a stabilized liquid (DuBourdieu 2014). This stabilized liquid format is a practical and inexpensive delivery method that allows the specific IgY to be delivered in watering systems to production animals or incorporation into other delivery formats such as soft chews that can be readily given to companion animals (Fig. 6).

The effective mechanism by which avian IgY's work is effective is by the same mechanism that mammalian $\operatorname{IgG}$ antibodies work in the animal to provide passive immunity. For example, bacteria E. coli strain K88 typically causes problems in production animals that result in diarrhea and possible death. Therefore, a vaccination program is used in chickens to create specific anti-E. coli $\mathrm{K} 88 \mathrm{IgY}$ antibodies. These specific antibodies found in the yolk of the egg are given orally to animals to prevent $E$. coli $\mathrm{K} 88$ from causing disease. This occurs when specific anti-E. coli $\mathrm{K} 88 \operatorname{IgY}$ antibodies bind to the pathogenic bacteria. This binding blocks the ability of the pathogen to bind to the mucin layer animals. 
in the GI tract of the animal. The pathogens are flushed out of the GI tract with the feces since they have been rendered unable to bind.

The total immunoglobulin content of eggs from hyperimmunized hens is identical to the total level of immunoglobulins found in conventional table eggs. However, the quantities of immunoglobulins to selected antigens are different in the two varieties of eggs. Additionally, both the table egg and the "immune" egg contain immunoregulatory factors, but eggs from hyperimmunized chickens may contain many times greater concentrations of individual factors as compared to regular eggs. Besides immunoglobulins, eggs contain a number of bioactive components, including phospholipids, cholesterol, lutein, zeaxanthin, and proteins, that possess a variety of proand/or anti-inflammatory properties. Two major categories of immune components are found in "hyperimmune" egg: (1) the immunoglobulins with neutralizing specificities against the stimulating pathogens and (2) the immunoregulatory factors that modulate cellular functions. The immunoglobulins provide local protection against gastrointestinal intoxication. The immunomodulatory mediators act directly on gastrointestinal surfaces and circulate systemically, affecting every immune, physical, metabolic, and neuroendocrine pathway in the body. These may have important implications for the pathophysiology of numerous chronic diseases and immune responses to acute injury (Andersen 2015). Given the essentiality of pro-inflammatory responses in normal immune defense against pathogens, further research into the role of egg intake on immunity is warranted and may lead to further commercial uses of eggs and $\operatorname{IgY}$ technology.

\section{Monoclonal Antibodies in Veterinary Use}

Biological medicine in humans, an intervention pioneered in the last 30 years, is now on the horizon for companion animals. This strategy includes the use of monoclonal antibodies (mAbs) to selectively target proteins such as cellular receptors or soluble molecules involved in disease pathogenesis. Such treatment holds the potential for targeted therapies of chronic diseases such as osteoarthritis, atopic dermatitis, or lymphomas in dogs and cats.

Monoclonal antibodies are antibodies that are made by identical immune cells that are all clones of a unique parent cell. Monoclonal antibodies have monovalent affinity, in that they bind to the same epitope. In contrast, polyclonal antibodies bind to multiple epitopes and are usually made by several different plasma cell lineages (Fig. 7).

Given almost any substance, it is possible to produce monoclonal antibodies that specifically bind to that substance; they can then serve to detect or purify that substance. This has become an important tool in biochemistry, molecular biology, and medicine. Therapeutic mAbs can be used medically to block disease-relevant proteins (e.g., cytokines or receptors on cells) and cancer and have gained significant use in humans. They can also be used to target viruses or bacteria and aid in their destruction and elimination. Veterinary medicine is only now incorporating this tool.

Despite the success of mAbs in human medicine, there are considerably fewer in the pipeline for veterinary medicine. This may be due to uncertain regulatory guidance in both Europe and the USA. These regulatory documents are written from the perspective of human medicine-based risk assessment and development. It is recognized that this may present a challenge to veterinary mAbs manufacturers to achieve the extent of characterization/quality control testing typically required for human mAbs. (EMA 2017). Regardless, the pet medicine industry is making strides to put mAbs into the market through basic research.

Early human therapeutic mAbs contained a high proportion of mouse-derived sequences (fully mouse or mouse/ human chimeric mAbs) that were recognized by the human immune system as foreign. This immune response triggered production of anti-mAbs, leading to reduced therapeutic efficacy. Subsequently, the design of humanized and fully human mAbs has resulted in a vast reduction in their immunogenicity, although most therapeutic mAbs may have some remaining immunogenicity that is not followed by apparent adverse clinical manifestations. These same issues hold true
Fig. 7 Polyclonal antibody compared to monoclonal antibody binding of antigens

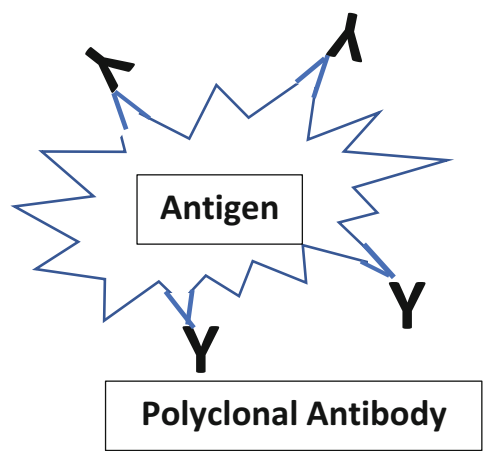

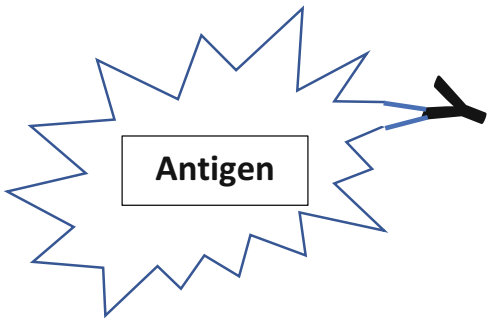

Monoclonal Antibody 
for making veterinary mAbs and utilizing canine mAbs for dogs that helps efficacy. It has been found that caninized antiIgE mAbs reduce IgE hypersensitivity in mite-sensitized beagles (Gearing et al. 2013). Caninized anti-nerve growth factor $\mathrm{mAb}$ (Webster 2014) significantly reduced pain scores (Webster et al. 2014) in dogs, and mAbs that neutralize the pruritogenic cytokine IL-31 in dogs reduced the pruritic response for 3 weeks after injection (Dunham et al. 2014).

One of the aspects regarding commercializing therapeutic antibodies involves regulation from the USDA. In 2015, two USDA-approved monoclonal antibody treatments for B-cell and T-cell lymphomas in dogs were granted. These mAbs fight lymphoma by targeting the protein CD20, which is commonly expressed in B-cell lymphoma (Ogilvie et al. 2014; Bulman-Fleming et al. 2014). While these particular mAbs were not commercially successful, they are part of a new approach for using therapeutic antibodies in veterinary medicine. Other companies are developing veterinary mAbs for cancer, allergies, and chronic inflammatory disease such as atopic dermatitis and for the control of pain associated with osteoarthritis in dogs and cats (Webster et al. 2014). The first $\mathrm{mAb}$ approved for veterinary use was in the European Union (BMJ 2017). It treats the clinical signs of atopic dermatitis in dogs, including itch and inflammation, for up to 1 month. The $\mathrm{mAb}$ treatment works by mimicking the activity of natural antibodies to selectively bind to and neutralize interleukin-31 (IL-31), a key protein involved in cell communication which triggers itching associated with atopic dermatitis in dogs. Because it neutralizes IL-31, it has been demonstrated not to interfere with the immune response, meaning that it does not induce unintended immunosuppression or enhancement.

Most therapeutic mAbs are delivered via intravenous, intramuscular, or subcutaneous injection. This is because antibodies can't be delivered orally because of breakdown in the stomach by acids or other factors found there. Various encapsulation methodologies are required in order to overcome this basic issue, and these methods should be forthcoming. Once injected, most therapeutic mAbs, like natural antibodies, have a long half-life (about 21 days). The absolute half-life for each is unique, depending upon its concentration, distribution of its target, and, if the mAb is directed to a cellsurface receptor, clearance and elimination of the target receptor. Therapeutic mAbs have two main safety advantages: (1) they have very specific targets, and (2) they don't have intracellular activity. As a result, there are few anticipated side effects and reactions although they can occur (Catapanoab and Papadopoulosc 2013). mAbs are eventually eliminated via intracellular catabolism in the lysosome, where they are broken down into peptides or amino acids that can be either reused for synthesis of new proteins or excreted via the urine.

\section{Concluding Remarks and Future Directions}

Antibodies for veterinary use have great potential for the future. Passive antibody therapy in the treatment of infectious diseases is a concept which dates back more than 120 years, to the 1890s, when the use of serum from immunized animals provided the first effective treatment options against infections with Clostridium tetani and Corynebacterium diphtheriae (Hey 2015). However, due to the discovery of penicillin by Fleming in 1928, and the subsequent introduction of the much cheaper and safer antibiotics in the 1930s, serum therapy was largely abandoned. But in more recent times, the broad and general use of antibiotics in human and veterinary medicine has resulted in the development of multiresistant strains of bacteria with limited or no response to existing treatments and thus a need for alternative treatment options. This situation can be partially attributed to the overuse of antibiotics as growth promoters for production animals and other indiscriminate use.

The combined specificity and flexibility of antibody-based treatments in providing passive immunity makes them very valuable tools for designing specific antibody treatments to infectious agents. These attributes have already caused a revolution in new antibody-based treatments in oncology and inflammatory diseases, with many approved products for human use. However, only very few mAbs are approved for veterinary use. mAbs therapies are expensive, and this has been a barrier for their development in the presence of inexpensive antibiotics. The use of antibiotics as growth promoters came to an end in 2017 in the USA with the rest of the world already limiting their use for this purpose manner (FDA 2015). This opens the door to new technologies and antibodies from monoclonal sources, chicken eggs, cow colostrum, or other sources to be among the chief contenders for limiting diseases in a safe manner and potentially to act as growth promoters. For that purpose, antibodies and antibodyderived treatments offer very attractive tools and attributes to neutralize infectious agents or modulate the immune system to enable effector cells to escape immunosuppressed conditions and contribute to the elimination of infections. The ability to raise antibodies to any target, and the ability to modulate effector functions, half-life, and size of the treatment units, makes antibodies ideal for tailoring treatments for specific infectious agents. However, more research into the use of antibodies as growth promoters will need to occur.

One area that researchers are looking to make better use of antibody treatments for veterinary use includes more use of mAbs. It has been predicted that minimal amino acid changes are needed to adapt an antibody from one species to another 
to avoid immune rejection. Using libraries of genetic information and algorithms to make sure that key amino acid sequences are recognized as "self" or "native" by the target species' immune system can reduce the chance of undesirable immune reactions. This will increase the advantages typical of mAbs for potency, safety, and a prolonged elimination half-life. Therefore, these second- and third-generation mAbs will be at the forefront of veterinary antibody technology along with IgY technology.

Molecular targets for therapeutic mAbs, IgY, and colostrum IgG in animals should (1) be involved in clinical signs or disease mechanism and (2) not have redundant pathways compensating for blockade of the intended target. The validity of blocking a molecule or eliminating a cell type must also be weighed against the importance of this protein or cell for desirable normal body functions. It is possible to speculate on uses of these antibodies in companion animals. These might include immune-mediated hemolytic anemias/ thrombopenias, myasthenia gravis, and autoimmune blistering diseases such as pemphigus, among other conditions. For cancer, the use of $\mathrm{mAb}$ or $\operatorname{IgY}$ therapy targeting B-lymphocytes will be valuable for B-cell lymphomas in dogs and cats. In allergic diseases, the use of mAbs to inhibit production of $\mathrm{IgE}$ via its promoting cytokines such as interleukins IL-4/IL-13, their cytokine receptors, or IgE itself might be beneficial in dogs and cats with IgE-mediated atopic dermatitis or food allergies. The itch sensation itself could be altered, at least theoretically, by antibodies targeting itch-promoting cytokines such as IL-31, nerve growth factor, thymic stromal lymphopoietin, or neuromediators involved in itch transmission. In arthritis therapeutic mAbs that inhibit pro-inflammatory cytokines (TNF-alpha, IL1, etc.) or their receptors are likely to be of benefit in treating dogs and cats with arthritis. The usefulness of anti-NGF mAbs as an analgesic must be confirmed. In autoimmune diseases, the use of mAbs specific for B-lymphocyte surface proteins could theoretically lead to reduced production of autoantibodies.

Veterinary vaccines have had, and continue to have, a major impact not only on animal health and production but also on human health, through increasing safe food supplies and preventing animal-to-human transmission of infectious diseases. The continued interaction between animals and human researchers and health professionals will be of major importance for adapting new technologies, providing animal models of disease, and confronting new and emerging infectious diseases. One area of research where more information is needed is on factors that limit efficacy of vaccination IFOMA, particularly in calves $<1$ month old. This is a complex issue. However, research continues to evolve in the area of newborn calf vaccinations.

Passive immunity provided by chicken egg antibodies will gain increasing use in production animals. There is no doubt that chicken Abs can be produced and used, with minor modifications, in similar ways to mammalian Abs. It can also be said that, depending on the circumstances, the use of IgY Abs often has significant advantage over the use of mammalian Abs. However, from a realistic point of view, IgY Abs probably will not be able to completely replace the use of IgG Abs in diagnostic systems in the near future (Schade et al. 2005). Chickens have the potential to be used to complete the spectrum of animals that have been used for $\mathrm{Ab}$ production. However, a prerequisite is to make $\operatorname{IgY}$ technology more popular and to convince the scientific community of its significant advantages. An interesting possibility for the future is the production of chicken mAbs. These would combine the advantages of mAbs with the advantages of chicken Abs. It is to be expected that studies on the therapeutic or prophylactic use of IgY Abs will be intensified in the future. In particular, because of the increasing resistance of microorganisms to antibiotics, research on all aspects related to the development of specific IgY against pathogenic microorganisms will have to be intensified.

In conclusion, the next decade will see continued development of therapeutic mAbs, IgYs, and colostrum antibodies for production and companion animals in both treatment and prevention. These highly specific molecules are likely to prove beneficial to uniquely target disease mechanisms without the side effects associated with broad-spectrum pharmacotherapy. While vaccines will continue to play a very important role in maintaining the health of animals by active immunity, antibodies that provide passive immunity will be an increasing part of the arsenal available to veterinarians to promote growth in production animals in a safe manner and to maintain health in companion animals.

\section{References}

Alabama A\&M and Auburn Universities (2018) Vaccinations for the swine herd. http://www.aces.edu/pubs/docs/A/ANR-0902/ANR0902.pdf

Andersen CJ (2015) Bioactive egg components and inflammation. Nutrients 7(9):7889-7913

BMJ (2017) First antibody therapy in veterinary medicine launched for dogs in the UK. Vet Rec 181:6-7

Brandtzaeg P (2010) The mucosal immune system and its integration with the mammary glands. J Pediatr 156:S8-S15

Bulman-Fleming J, Rosenberg M, Hansen G et al (2014) Treatment of canine B-cell lymphoma with doxorubicin with or without an antiCD20 monoclonal antibody: an open-label pilot study. In: Proceedings, 34th Annual Veterinary Cancer Society Conference, St. Louis, MO, USA

Buragohain M, Dhale GS, Ghalsasi GR et al (2012) Evaluation of hyperimmune hen egg yolk derived anti-human rotavirus antibodies (AntiHRVIgY) against rotavirus infection. World J Vacc 2:73-84

Capolunghi F, Rosado MM, Sinibaldi M et al (2013) Why do we need IgM memory B cells? Immunol Lett 152(2):114-120

Catapanoab AL, Papadopoulose N (2013) The safety of therapeutic monoclonal antibodies: implications for cardiovascular disease and targeting the PCSK9 pathway. Atherosclerosis 228:18-28 
Chamorro MF, Walz PH, Haines DM et al (2014) Comparison of levels and duration of detection of antibodies to bovine viral diarrhea virus 1 , bovine viral diarrhea virus 2 , bovine respiratory syncytial virus, bovine herpesvirus 1 , and bovine parainfluenza virus 3 in calves fed maternal colostrum or a colostrum-replacement product. Can J Vet Res 78(2):81-88

Chamorro MF, Woolums A, Walz PH (2016) Vaccination of calves against common respiratory viruses in the face of maternally derived antibodies (IFOMA). Anim Health Res Rev 17(2):79-84

Chelack BJ, Morley PS, Haines DM (1993) Evaluation of methods for dehydration of bovine colostrum for total replacement of normal colostrum in calves. Can Vet 34(7):407-412

Chen K, Cerutt A (2011) The Function and regulation of immunoglobulin D. Curr Opin Immunol 23(3):345-352

Chigerwe M, Tyler JW, Summers MK et al (2009) Evaluation of factors affecting serum IgG concentrations in bottle-fed calves. J Am Vet Med Assoc 234:785-789

Clarkson MJ, Faull WB, Kerry JB (1985) Vaccination of cows with clostridial antigens and passive transfer of clostridial antibodies from bovine colostrum to lambs. Vet Rec 116(17):467-469

Combs DK, Bringe AN, Crabb JH et al (1993) Protection of neonatal calves against K99-E. coli and corona virus using a colostrumderived immunoglobulin preparation. Agri-Practice 14(5):13-16

Cook ME, Butz D, Li GM et al (2003) Conjugated linoleic acid enhances immune responses but protects against the collateral damage of immune events. In: Sébédio JL, Christie WW, Adlof R (eds) Advances in conjugated linoleic acid research, vol 2. AOCS Press, Champaign, IL, pp 283-291

Cook S, Bach S, Stevenson S et al (2005) Orally administered antiEscherichia coli O157: H7 chicken egg yolk antibodies reduce fecal shedding of the pathogen by ruminants. Can J Anim Sci 85:291-299

Cui HZ, Zhang JL, Zhang H et al (2012) Study and application of the hyperimmunized yolk antibodies against TGEV and PEDV in piglets. China Anim Husb Vet Med 39:173-175

Devillers N, Le Dividich J, Prunier A (2011) Influence of colostrum intake on piglet survival and immunity. Animal 5(10):1605-1612

Diraviyam T, Zhao B, Wang Y et al (2014) Effect of chicken egg yolk antibodies (IgY) against diarrhea in domesticated animals: a systematic review and meta-analysis. PLoS One 9(5):e9771

DuBourdieu D (2014) Stabilized liquid egg material for extended shelf life. United States Patent 8,828,422

Dunham S, Teel J, Bammert G et al (2014) Evaluation of anti-IL-31 monoclonal antibodies in a model of IL-31-induced pruritus in Beagle dogs. Vet Dermatol 25:403

El-Ghany WA (2011) Comparison between immunoglobulins IgY and the vaccine for prevention of infectious Bursal disease in chickens. Global Vet 6(1):16-24

EMA (2017) EMA/CVMP/ADVENT/307606/2017 Committee for Medicinal Products for Veterinary Use (CVMP). Questions and answers on monoclonal antibodies for veterinary use European Medicines Agency. Accessed 7 Dec 2017

Erb KJ (2007) Allergic disorders and IgE-mediated immune responses: where do we stand? Eur J Immunol 37(5):1170-1173

Fagarasan S, Honjo T (2003) Intestinal IgA synthesis: regulation of front-line body defenses. Nature Rev Immunol 3(1):63-72

Farooq A, Rabbani M, Muhammad K et al (2012) Passive immunization in infectious bursal disease virus infected birds using chemically purified immune yolk immunoglobulins (IgY). Afr J Microbiol Res 6:2993-2998

Fayer R, Andrews C, Ungar BL et al (1989) Efficacy of hyperimmune bovine colostrum for prophylaxis of cryptosporidiosis in neonatal calves. J Parasitol 75(3):393-397

Fenger CK, Tobin T, Casey PJ et al (2016) Enhanced bovine colostrum supplementation shortens the duration of respiratory disease in thoroughbred yearlings. J Equine Vet Sci 42:77-81
Food and Drug Administration (2015) Food and drug administration center for veterinary medicine veterinary feed directive guidance for industry \#120

Ford RB, Larson LJ, McClure KD et al (2017) American animal hospital association canine vaccination guidelines. Trends Magaz 27-35.

Gearing DP, Virtue ER, Gearing RP et al (2013) A fully caninised antiNGF monoclonal antibody for pain relief in dogs. BMC Vet Res 9:226

Germine SS, Ebied MH, Ibrahim FK et al (2011) Field evaluation of egg yolk antibodies in prevention and treatment of enteric colibacillosis in calves. Benha Vet Med J (special issue I):108-114

Gitlin AG, Nussenzweig MC (2015) Immunology: fifty years of B lymphocytes. Nature 517:139-114

Godden SM, Smolenski DJ, Donahue M et al (2012) Heat-treated colostrum and reduced morbidity in preweaned dairy calves: results of a randomized trial and examination of mechanisms of effectiveness. J Dairy Sci 95:4029-4040

Gould HJ, Sutton BJ, Beavil AJ et al (2003) The biology of IgE and the basis of allergic disease. Ann Rev Immunol 21:579-628

Graczyk TK, Cranfield MR, Bostwick EF (1999) Hyperimmune bovine colostrum treatment of moribund Leopard geckos (Eublepharis macularius) infected with Cryptosporidium spp. Vet Res 30 (4):377-382

Gulliksen SM, Lie KI, Solverod L et al (2008) Risk factors associated with colostrum quality in Norwegian dairy cows. J Dairy Sci 91:704-712

Hamal KR, Burgess SC, Pevzner IY et al (2006) Maternal antibody transfer from dams to their egg yolks, egg whites, and chicks in meat lines of chickens. Poult Sci 85(8):1364-1372

Hey A (2015) History and practice: antibodies in infectious diseases. Microbiol Spectr 3(2):AID-0026-2014

Holmgren J, Czerkinsky C (2005) Mucosal immunity and vaccines. Nat Med 11(4 Suppl):S45-S53

Hurley WL, Theil PK (2011) Perspectives on immunoglobulins in colostrum and milk. Nutrients 3(4):442-474

Ishikawa H, Kanamori Y, Hamada H et al (2005) Development and function of organized gut-associated lymphoid tissues. In: Mestecky J, Lamm M, Strober W, Bienenstock J, McGhee JR, Mayer L (eds) Mucosal immunology, 3rd edn. Academic, Burlington, MA

Li C, Liu Y, Jiang Y, Xu N, Lei J (2017) Immunomodulatory constituents of human breast milk and immunity from bronchiolitis. Ital J Pediatr 43:8

Li-Chan E, Kummer A, Losso JN et al (1994) Survey of immunoglobulin $\mathrm{G}$ content and antibody specificity in cow's milk from British Columbia. Food Agric Immunol 6:443-451

Marchalonis JJ, Jensen I, Schluter SF (2002) Structural, antigenic and evolutionary analyses of immunoglobulins and $\mathrm{T}$ cell receptors. J Mol Recogn 15(5):260-271

Marcotte H, Hammarström L (2015) Chapter 71 - Passive immunization: toward magic bullets. In: Mucosal immunology, vol 2, 4th edn. Academic, Amsterdam, pp 1403-1434

Mayer B, Doleschall M, Bender B, Bartyik J et al (2005) Expression of the neonatal $\mathrm{Fc}$ receptor $(\mathrm{FcRn})$ in the bovine mammary gland. J Dairy Res 72:107-112

Meeusen NT, Walker J, Peters A et al (2007) Current status of veterinary vaccines. Clin Microbiol Rev 20(3):489-510

Meganck V, Hoflack G, Opsomer G (2014) Advances in prevention and therapy of neonatal dairy calf diarrhoea: a systematical review with emphasis on colostrum management and fluid therapy. Acta Vet Scand 56:75

Missouri (2018) Programs for the cow/calf operation. http://extension. missouri.edu/ozark/documents/Vaccination\%20Protocol\%20Script. pdfVaccination 
Morrill KM, Conrad E, Lago A et al (2011) Nation-wide evaluation of quality and composition of colostrum fed to dairy calves in the United States. J Dairy Sci 94(E-Suppl) 1):277 10

Mueller RS, Janda J, Jensen-Jarolim E et al (2016) Allergens in veterinary medicine. Allergy 71(1):27-35

Naciri M, Mancassola R, Répérant J et al (1994) Treatment of experimental ovine cryptosporidiosis with ovine or bovine hyperimmune colostrum. Vet Parasitol 53:173-190

Nagler-Anderson C (2001) Man the barrier! Strategic defences in the intestinal mucosa. Nat Rev Immunol 1:59-67

Niewiesk S (2014) Maternal antibodies: clinical significance, mechanism of interference with immune responses, and possible vaccination strategies. Front Immunol 5:446

Ogilvie G, Proulx D, Van Horn L et al (2014) Treatment of canine B-cell lymphoma with chemotherapy and a canine anti-CD20 monoclonal antibody: a prospective double-blind, randomized, placebocontrolled study. In: Proceedings, 34th Annual Veterinary Cancer Society Conference, St. Louis, MO

Pakkanen R, Aalto J (1997) Growth factors and antimicrobial factors of bovine colostrum. Int Dairy J 7(5):285-297

Pennsylvania State University (2017). Colostrum and replacer. https:// extension.psu.edu/colostrum-supplements-and-replacer

Pfister K, Turner K, Currie A et al (1983) IgE production in rat fascioliasis. Parasit Immunol 5(6):587-593

Pommer JL (2010) Sheep antiserum as an antibody supplement in newborn lambs. Sheep Goat Res J 25:45-48

Preud'homme JL, Petit I, Barra A et al (2000) Structural and functional properties of membrane and secreted IgD. Mol Immunol 37:871-887

Quigley JD, Drewry JJ (1998) Nutrient and immunity transfer from cow to calf pre- and post-calving. J Dairy Sci 98(10):2779-2790

Schade R, Sarmiento R, Calzado EJ et al (2005) Chicken egg yolk antibodies ( $\operatorname{IgY}$-technology): a review of progress in production and use in research and human and veterinary medicine. Altern Lab Anim 33(2):129-154

Selim SA, Cullor JS, Oelsner IE (1995) Passive immunotherapy in neonatal calves - I. Safety and potency of a J5 Escherichia coli hyperimmune plasma in neonatal calves. Vaccine 13(15):1449-1453

Shibata I, Ono M, Mori M (2001) Passive protection against porcine epidemic diarrhea (PED) virus in piglets by colostrum from immunized cows. J Vet Med Sci 63(6):655-658

Snoeck V, Peters IR, Cox E (2006) The IgA system: a comparison of structure and function in different species. Vet Res 37(3):455-467
Stewart-Brown B (2018) Vaccination programs in poultry. http://www. merckvetmanual.com/poultry/nutrition-and-management-poultry/ vaccination-programs-in-poultry

Stilwell G, Carvalho RC (2011) Clinical outcome of calves with failure of passive transfer as diagnosed by a commercially available IgG quick test kit. Can Vet J 52(5):524-526

Sty AC, Sangild PT, Skovgaard K et al (2006) Spray dried, pasteurized bovine colostrum protects against gut dysfunction and inflammation in preterm pigs. J Pediatr Gastroenterol Nutr 63(2):280-287

Sugita-Konishi Y, Shibata K, Yun SS, Hara-Kudo Y et al (1996) Immune functions of immunoglobulin $\mathrm{Y}$ isolated from egg yolk of hens immunized with various infectious bacteria. Biosci Biotechnol Biochem 60(5):886

Thomas HS (2017, January) Precalving vaccination programs for cows. 46 Herefor World pp 46-47

Trotz-Williams LA, Leslie KE, Peregrine AS (2008) Passive immunity in Ontario dairy calves and investigation of its association with calf management practices. J Dairy Sci 91:3840-3849

Vega C, Bok M, Chacana P, Saif L et al (2011) Egg yolk IgY: protection against rotavirus induced diarrhea and modulatory effect on the systemic and mucosal antibody responses in newborn calves. Vet Immunol Immunopathol 142:156-169

Vega CG, Bok M, Vlasova AN et al (2012) IgY antibodies protect against human rotavirus induced diarrhea in the neonatal gnotobiotic piglet disease model. PloS One 7:e42788

Vighi G, Marcucci F, Sensi L et al (2008) Allergy and the gastrointestinal system. Clin Exp Immunol 153(Suppl 1):3-6

Watanabe N, Bruschi F, Korenaga M (2005) IgE: a question of protective immunity in Trichinella spiralis infection. Trends Parasitol 21 (4): $175-178$

Webster RP, Anderson GI, Gearing DP (2014) Canine brief pain inventory scores for dogs with osteoarthritis before and after administration of a monoclonal antibody against nerve growth factor. Am J Vet Res 75:532-535

Woolley JA, Landon J (1995) Comparison of antibody production to human interleukin-6 (IL-6) by sheep and chickens. J Immunol Methods 178:253-265

Woolums AR (2007) Vaccinating calves: new information on the effects of maternal Iimmunity. The AABP Proc 40:10-17

Yolken RH, Losonsky GA, Vonderfecht S et al (1985) Antibody to human rotavirus in cow's milk. N Engl J Med 312(10):605-610 